\title{
Erythropoietin, protein, and iron supplementation and the prevention of anaemia of prematurity
}

\author{
Anne Grete Bechensteen, Per Hågå, Sverre Halvorsen, Andrew Whitelaw, Knut Liestøl, \\ Rolf Lindemann, Jens Grøgaard, Marit Hellebostad, Ola Didrik Saugstad, Morten Grønn, \\ Ludvig Daae, Harald Refsum, Even Sundal
}

University of Oslo, Norway, Department of Paediatrics, Ullevå Hospital

Anne Grete Bechensteen Per Hågå

Sverre Halvorsen

Rolf Lindemann

Marit Hellebostad

Department of Paediatrics, Aker Hospital

Jens Grøgaard

Andrew Whitelaw

Institute of Informatics Knut Liestøl

Paediatric Research Institute and

Department of

Paediatrics, The

National Hospital

Ola Didrik Saugstad

Department of

Paediatrics, Akershus

Central Hospital

Morten Grønn

Department of Clinical Chemistry, Ullevål

Hospital

Ludvig Daae

Laboratory for Clinical Physiology, Ullevå

Hospital

Harald Refsum

Cilag, Sandvika

Even Sundal

Correspondence to:

Dr Anne Grete Bechensteen,

Department of Paediatrics,

Ullevål Hospital, 0407 Oslo,

Norway.

Accepted 6 January 1993

\begin{abstract}
The effectiveness of recombinant human erythropoietin ( $\mathrm{r}$-HuEpo) in raising haemoglobin concentrations in very low birthweight infants was examined in a randomised multicentre study. Twenty nine 'healthy' appropriate for gestational age infants with birth weights $900-1400 \mathrm{~g}$ entered the study at 3 weeks of age. All infants received breast milk supplemented with 9 g/l human breast milk protein from 3 to 8 weeks of age. Eighteen mg iron was given daily from week 3 and was doubled if serum iron concentration fell below $16.0 \mu \mathrm{mol} / \mathrm{h}$. Fourteen infants were randomised to receive $100 \mathrm{U} / \mathrm{kg}$ r-HuEpo subcutaneously three times a week from week 3 to week $7 ; 15$ infants served as controls.
\end{abstract}

After one week reticulocyte and haemoglobin concentrations were significantly higher in the r-HuEpo treated group and the haemoglobin values remained significantly higher throughout r-HuEpo treatment and at the concentrations observed in full term infants. No adverse effects were associated with the treatment.

In stable very low birthweight infants with optimal iron and protein intakes, moderate dose r-HuEpo can produce significant gains in red cell production that may be clinically useful.

(Arch Dis Child 1993; 69: 19-23)

Hitherto, blood transfusion has been the chief means of correcting anaemia in preterm infants. Blood transfusion has small, but significant risks and thus any measures that could increase the infant's own production of erythrocytes and reduce the need for transfusion would be welcome.

Haemoglobin concentrations decrease in all infants during the first few months after birth and this is termed the physiological anaemia of infancy. In preterm infants the fall in haemoglobin is greater and more rapid, reaching a nadir at 5-8 weeks. ${ }^{1}$ This early anaemia of prematurity is mainly due to inadequate production of red cells, although repeated blood sampling plays a part in some infants. Several studies have found low serum concentrations of erythropoietin during this period and it has been suggested that the concentrations are inappropriately low for the degree of anaemia. ${ }^{2-4}$ Thus a reduced capacity for erythropoietin production has been inferred. In vitro studies have shown that erythroid pro- genitors from the marrow and blood of such infants respond normally to erythropoietin. ${ }^{56}$ Thus replacement treatment with recombinant human erythropoietin ( $r-H u E p o$ ) seems a logical approach. Several studies have investigated r-HuEpo treatment in preterm infants. $^{7-13}$ So far only the pilot study of Shannon et al $^{12}$ with only four patients in each group and the study by Carnielli et al ${ }^{13}$ employing very large doses of r-HuEpo have shown clear evidence of increased erythropoiesis.

When planning the present study on r-HuEpo treatment of preterm infants, we considered three observations to be particularly pertinent:

(1) Human milk protein supplementation alleviates the early anaemia in preterm infants fed human milk, suggesting that the available supply of protein provided by ordinary breast milk is insufficient for red cell production during this period of very rapid growth. ${ }^{14}$

(2) The early anaemia in rabbits, mice, and pigs is completely abolished by plentiful supplies of iron, indicating that sufficient 'available iron' is essential for increased erythropoiesis during rapid growth. ${ }^{15-17}$

(3) The erythropoietic response to r-HuEpo treatment in patients with renal failure is dependent on sufficient amounts of available iron. ${ }^{18}$

The object of the present study was to determine whether very low birthweight infants respond to exogenous erythropoietin with increased erythropoiesis. In order to ensure non-restrictive erythropoiesis they were richly supplemented with protein and iron.

\section{Subjects and methods}

STUDY POPULATION

The trial was designed as a randomised, open, controlled study with four participating centres. Based upon a statistical power study it was decided to include 15 infants in each group.

Twenty nine premature babies were enrolled in the trial at 3 weeks of age. Strict inclusion and exclusion criteria were set to make the study population as homogenous as possible. Inclusion criteria were: (1) birthweight 900-1400 $\mathrm{g}$ and (2) birth weight above the 3 rd centile for gestational age (AGA). ${ }^{19}$ Exclusion criteria were: (1) ongoing ventilator treatment, (2) fractional inspired oxygen $\left(\mathrm{FIO}_{2}\right)>40 \%$, (3) previous or present steroid medication, (4) blood transfusion less than 96 hours before start of study, (5) ongoing 
infection with antibiotic treatment started less than 96 hours before start of study, (6) obvious signs/symptoms of neurological impairment, (7) $\mathrm{ABO} / \mathrm{Rh}$ incompatibility or other haematological disease, (8) other disease or illness (renal disease, heart disease, syndromes, etc), and (9) parenteral nutrition. The objective was to enrol 'healthy' infants only. The babies were withdrawn from the study if serious infection (defined as antibiotic treatment for more than 72 hours) or increased oxygen demands (defined as $\mathrm{FIO}_{2}>40 \%$ for more than 24 hours) occurred.

The infants were randomised separately at each centre to receive r-HuEpo treatment or serve as controls. Randomisation was performed by prenumbered sealed envelopes.

Written informed consent was obtained from the parents in all cases. The study was approved by the regional ethics committee.

\section{METHODS}

The study period lasted from 3 to 8 weeks of age with an additional assessment at 16 weeks.

\section{Treatment and feeding regimen}

The r-HuEpo (Eprex, Cilag, $2000 \mathrm{U} / \mathrm{ml}$ ) was given subcutaneously in a dose of $100 \mathrm{U} / \mathrm{kg}$ three times a week from 3 to 7 weeks of age.

All infants received $170-180 \mathrm{ml} / \mathrm{kg} /$ day of human milk from either their mothers or the milk bank. The milk was fortified from week 3 to week 8 with pasteurised, freeze dried human milk protein in the amount of $9 \mathrm{~g} / \mathrm{l}$ in accordance with Rönnholm and Siimes. ${ }^{14}$ Total protein intake was approximately 3.0 $\mathrm{g} / \mathrm{kg} /$ day.

Oral iron supplementation, $18 \mathrm{mg}$ iron/day regardless of weight, given as iron fumarate (Neo-Fer, Nyco), was commenced at the start of the study ( 3 weeks of age). If serum iron concentration fell below $16.0 \mu \mathrm{mol} / \mathrm{l}$ (90 $\mu \mathrm{g} / 100 \mathrm{ml}$ ), the dose was increased to $36 \mathrm{mg}$ iron/day. At the end of the study period ( 8 weeks) the dose was reduced to $18 \mathrm{mg} /$ day, which is the routine supplement for preterm infants in Norway.

\section{Laboratory investigations}

An aliquot of $1.0-1.5 \mathrm{ml}$ of blood was collected once a week by heel prick after five minutes prewarming to measure haemoglobin, packed cell volume, red cell indices (mean corpuscular volume, mean corpuscular haemoglobin, mean corpuscular haemoglobin concentration), white cell count, reticulocytes, serum iron, ferritin, sodium, potassium, calcium, phosphate, albumin, protein, urea, and creatinine. The blood samples were analysed in one laboratory with automated instruments. For the haematology Ortho-ELT 800/WS Westwood was used. Differential and reticulocyte counts were determined manually. Reticulocytes were determined by counting 2000 erythrocytes from coded blood smears.

Blood pressure was recorded daily by noninvasive oscillometric technique. Weight was measured daily, length and head circumference weekly.

Indications for blood transfusion were: (1) haemoglobin concentration below $80 \mathrm{~g} / \mathrm{l}$ or (2) otherwise at the discretion of the clinician caring for the infant according to symptoms and signs.

\section{STATISTICAL EVALUATION}

Tests of treatment effects were based on conventional regression techniques. Initial values (at age 3 weeks) were used as covariates to compensate for differences in initial values and to increase the power of the tests. The regression analyses revealed no need to take into account differences between hospitals or in birth weights and gestational ages. Overall treatment effects and treatment-time interactions were assessed using multivariate analyses of covariance for repeated measurements; the initial values employed as covariate. ${ }^{20}$ Depending on the distribution of the variables, a linear scale or logarithmic transformation was used.

Four infants received blood transfusions (all were controls). Using their haemoglobin and packed cell volume values obtained during the first 1-2 weeks after transfusion would bias the results, as would treating the values as missing (as the reason for each transfusion was a low haemoglobin value). We have therefore used linear interpolation over the two weeks after transfusion. An alternative technique, using regression analysis, gave very similar values. It should be noted that the main conclusion did not depend on this interpolation procedure; the largest difference between the control and treatment groups was found at age 7 weeks while the interpolation only affected ages 4-6 weeks.

One infant in the control group was excluded at age 6 weeks due to suspected septicaemia. The baby's data for age 3-6 weeks have been included in the analyses.

The analyses of all main variables have been repeated on the subgroup obtained by eliminating the data from the excluded infant and from the infants with initial haemoglobin concentrations above $150 \mathrm{~g} / 1$ or below $90 \mathrm{~g} / 1$. Results were very close to those obtained for the complete data set.

\section{Results}

The table shows the pretreatment characteristics. The treatment and control groups were similar with respect to birth weight, gestational age, sex ratio, weight at entry, and baseline haematological values.

Reticulocytes, both in percentage of red cells and in absolute numbers, increased rapidly and significantly $(p<0.0001)$ after one week of r-HuEpo treatment (fig 1). Significant treatment effects on reticulocyte values were found after one, two, and three weeks of treatment. In the control group the reticulocyte counts showed the normal rise and were significantly higher at 4 to 8 weeks of life 
compared with initial values $(p<0.01)$ (fig 1 ). During the last week of r-HuEpo treatment (6 to 7 weeks of age) there was a small decline in reticulocyte count $(\mathrm{p}<0.05)$, but a highly significant fall was observed after the cessation of r-HuEpo treatment at 7 weeks of age $(p<0.0001)$.

Figure 2 displays the haemoglobin and packed cell volume values. The treatment effect was already significant after one week (age 4 weeks), and this effect was sustained throughout the treatment period. The lowest mean haemoglobin concentration in the $\mathrm{r}$-HuEpo group was $112 \mathrm{~g} / \mathrm{l}$ at 5 weeks of age while that of the controls was $98 \mathrm{~g} / \mathrm{l}$ (week 7). The red cell indices were similar in both groups throughout the study.

All but three infants (two r-HuEpo treated, one control) required an increase in iron dosage due to serum iron concentration less than $16 \cdot 0$ $\mu \mathrm{mol} / 1$. Serum iron fell initially in the $\mathrm{r}-\mathrm{HuEpo}$ treated group. After one week of treatment they had significantly lower values than the controls $(14 \mu \mathrm{mol} / / v 19 \mu \mathrm{mol} / \mathrm{l})$. Thereafter the concentrations were equivalent. Serum ferritin concentrations displayed the expected fall in both groups, ${ }^{21}$ and there were no significant differences between them. During the study period four infants in the control group were transfused with red blood cells, none in the r-HuEpo group.

There were no significant differences between the groups in total white blood cell and neutrophil counts. No case of neutropenia (neutrophils $<10^{9} / 1$ ) was observed during the r-HuEpo treatment. One control infant had neutropenia at age 7 and 8 weeks. One r-HuEpo treated infant had $0.9 \times 10^{9} / 1$ neutrophils at age 16 weeks, that is nine weeks after the last $r$-HuEpo injection. Platelet counts increased slightly during the study

Pretreatment characteristics of study infants. Values are mean (range)

\begin{tabular}{lcc}
\hline & $r$-HuEpo group & Control group \\
\hline $\begin{array}{l}\text { Sex (F/M) } \\
\text { Gestational age }\end{array}$ & $8 / 6$ & $7 / 8$ \\
$\quad$ (weeks) & $29 \cdot 6(27-31)$ & $29 \cdot 3(26-32)$ \\
Birth weight (g) & $1280(1030-1400)$ & $1238(910-1390)$ \\
Weight at entry (g) & $1423(1190-1650)$ & $1416(1027-1725)$ \\
Haemoglobin (g//) & $125(96-156)$ & $121(89-170)$ \\
Packed cell volume & $0 \cdot 36(0 \cdot 26-0 \cdot 45)$ & $0 \cdot 34(0 \cdot 25-0 \cdot 50)$ \\
Reticulocytes (\%) & $3 \cdot 7(1 \cdot 4-9 \cdot 9)$ & $3.3(0 \cdot 5-7 \cdot 8)$
\end{tabular}

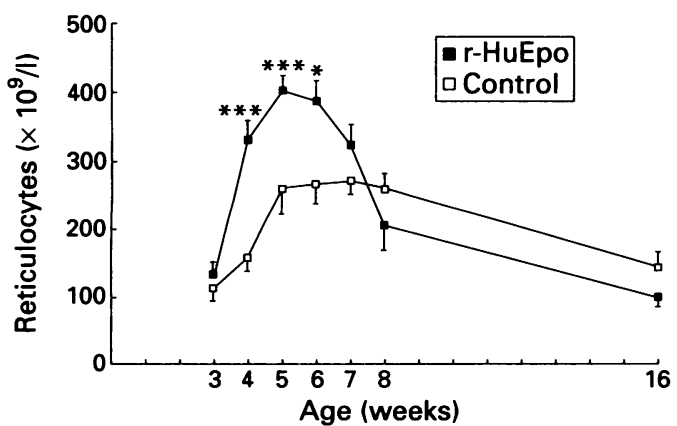

Figure 1 Absolute reticulocyte concentration in the $r$-HuEpo and control groups. Mean values; bars represent $S E$. Significant difference between treatment group and controls: ${ }^{\star} p<0.05,{ }^{\star \star \star} p<0.001$. period in both groups with no significant differences between them.

Growth (weight, length, and head circumference) was similar in the two groups with a weight gain of about $200 \mathrm{~g} /$ week, nearly corresponding to the in utero increments. ${ }^{19}$

No adverse effects were observed during the study. In particular, no hypertension or differences in blood pressure between the groups were encountered. There were no reactions to the injections, the oral iron, or the protein supplementation. All biochemical indices were within normal range. One patient in the control group was withdrawn from the study due to suspected, but at no time verified, septicaemia. His serum iron concentrations were within the normal range (at withdrawal: $14 \cdot 7 \mu \mathrm{mol} / \mathrm{l})$.

\section{Discussion}

In this randomised trial we have clear evidence that small preterm infants are able to respond to exogenous erythropoietin with increased erythropoiesis. The response was already seen after one week of r-HuEpo treatment in reticulocyte count as well as haemoglobin and packed cell volume values (figs 1 and 2). The nadir of haemoglobin concentration in the r-HuEpo treated group was $112 \mathrm{~g} / \mathrm{l}$. This value is similar to the nadir observed in full term infants. ${ }^{22} 23$ Thus the r-HuEpo treatment abolished the early anaemia of prematurity in these infants.

A point of interest is the drop observed in reticulocyte counts during the last week of r-HuEpo treatment and the first week after cessation of treatment at 7 weeks of age. The cause of this possible decline in erythropoiesis during and shortly after stopping r-HuEpo treatment might be that the endogenous
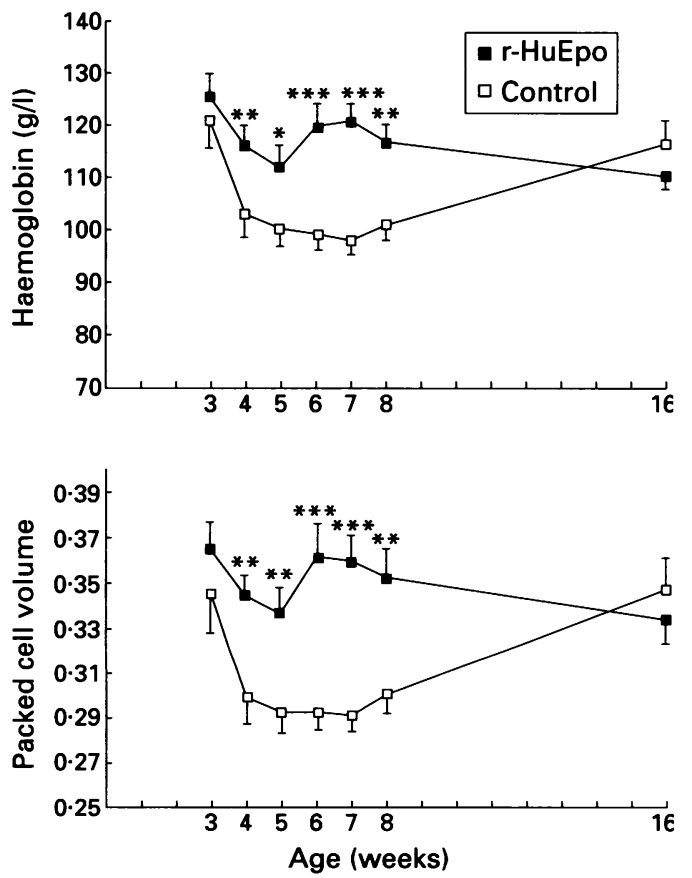

Figure 2 Haemoglobin and packed cell volume in the $r$-HuEpo and control groups. Mean values; bars represent $S E$. Significant difference between treatment groups and controls: ${ }^{\star} p<0.05,{ }^{\star \star} p<0.01,{ }^{\star \star \star}{ }^{*} p<0.001$. 
erythropoietin production ceases when haemoglobin increases.

Why did we obtain such a clear cut r-HuEpo response with moderate doses while others have failed to do so? ${ }^{8}$ We believe that the protein and iron supplements given to the infants in our study constitute the major explanation. Rönnholm and Siimes found that human milk protein supplementation ameliorates the early anaemia in preterms fed human milk. ${ }^{14}$ In the present investigation we provided the same kind of protein supplement in the same amount to both the r-HuEpo group and the controls during the study period. Our objective in this respect was to supply sufficient protein both for the increased erythropoiesis that $\mathrm{r}$-HuEpo treatment could cause, and to ensure enough protein for the rapid growth of the preterm infant at this age. We were concerned that the artificial hormone stimulation could divert protein needed for essential growth or other organs into red cell production if a deficiency or marginal provision of available protein occurred.

Functional iron deficiency during $\mathrm{r}-\mathrm{HuEpo}$ treatment of older subjects has been frequently reported. ${ }^{24}$ It is seen in the presence of normal and even increased concentrations of storage iron. ${ }^{25}$ The cause seems to be that the rate of supply of available iron to the expanding and responding erythron mass is not high enough. ${ }^{24}$ This state in the human corresponds to what is seen in the neonatal rabbit in which parenteral iron increases red cell production to such an extent that the animals experience no early anaemia whatsoever. This effect of parenteral iron occurs even though the animals have abundant storage iron. ${ }^{15}$ Based on these established findings we considered a rich supply of iron to be essential for fulfilling the requirements of erythropoiesis in the r-HuEpo stimulated bone marrow. Because of potentially deleterious effects ${ }^{26}$ we considered parenteral iron provision to be unethical. By international standards the regular Norwegian preterm iron dose of $18 \mathrm{mg}$ iron commenced at 6 weeks of age is high. This dose was started at 3 weeks of age (beginning of the study period) and doubled if serum iron fell below 16.0 $\mu \mathrm{mol} / \mathrm{l}$. No side effects of the iron medication were observed.

As earlier investigations of preterm infants failed to document an effect of r-HuEpo, the need for studies employing large doses of the hormone was called for. 891213 Our r-HuEpo dose of $300 \mathrm{U} / \mathrm{kg} /$ week is low compared with that of most ongoing investigations in preterms in which, for instance, up to $1200 \mathrm{U} / \mathrm{kg} /$ week are being used. On the other hand, our dose seems, at first sight, higher than the dose recommended for adult patients with end stage renal failure. However, calculated on the basis of body surface area rather than body weight, the doses are comparable: $30 \mathrm{U} / \mathrm{kg}$ in an adult of $75 \mathrm{~kg} / 180 \mathrm{~cm}$ corresponds to the same dose $/ \mathrm{m}^{2}$ body surface as $100 \mathrm{U} / \mathrm{kg}$ in an infant of $1.4 \mathrm{~kg} / 41 \mathrm{~cm}$. The reason for the lack of effect in other studies on preterm infants might be insufficiency of substrate (protein, iron) rather than insufficient r-HuEpo dosage.
The aetiology of the early anaemia of prematurity is still not clear. The observed stimulation of the erythropoiesis by exogenous erythropoietin does not necessarily prove that a lack of endogenous erythropoietin is the cause. In all other age groups all normal individuals will respond with increased red cell production following the $\mathrm{r}-\mathrm{HuEpo}$ doses given.

No adverse effects of r-HuEpo were observed, neither hypertension nor local or systemic reactions to the injections. Neutropenia, suggested as side effect of r-HuEpo treatment in preterm infants, ${ }^{7}{ }^{10}$ was not observed in our study. In the uncontrolled pilot study of Halpérin et al thrombocytosis as a side effect was postulated. ${ }^{7}$ We observed no differences between the groups in our study, and a rise in platelet count appears to be a normal phenomenon in preterm infants. ${ }^{27}$

The present study is too limited to answer whether all preterms would benefit from r-HuEpo treatment. Our aim was to establish whether the preterm infant is able to respond to exogenous erythropoietin with increased red cell production during the time of the early anaemia. We chose a selected group to answer this: healthy, orally fed, well nourished infants with birth weights $900-1400 \mathrm{~g}$ and appropriate for gestational age who were studied at 3-8 weeks of age. The marked increase in red cell production we have demonstrated, however, may be of significant clinical value and reduce the need for transfusion. It remains to be seen whether smaller and sick infants respond to $\mathrm{r}-\mathrm{HuEpo}$ in the same fashion, as well as how early after birth treatment can be effective. The need for securing adequate nutrition (iron, protein, and perhaps other essentials) might in such infants be even more crucial.

We thank the nursing staff and the laboratory personnel of the participating hospitals for their invaluable help and assistance. The skilful technical assistance of Kirsten Østbye is gratefully acknowledged.

We thank Cilag for their financial support and provision of Eprex. AGB is the recipient of a research fellowship from the
E Eprex. AGB is the recipien
Norwegian Cancer Society.

The financial support of Semper AB, Sweden for the preparation of the freeze dried human milk protein is gratefully acknowledged.

1 O'Brian RT, Pearson HA. Physiological anemia of the newborn infant. $\mathcal{F}$ Pediatr 1971; 79: 132-8.

2 Brown MS, Phibbs RH, Garcia JF, Dallman PR. Postnatal changes in erythropoietin levels in untransfused premature infants. F Pediatr 1983; 103: 612-7.

3 Stockman JA, Graeber JE, Clark DA, McClellan K, Garcia JF, Kavey REW. Anemia of prematurity: determinants of the erythropoietin response. $\mathcal{F}$ Pediatr $1984 ; 105: 786-92$

4 Brown MS, Garcia JF, Phibbs RH, Dallman PR. Decrease response of plasma immunoreactive erythropoietin to 'available oxygen' in anemia of prematurity. $\mathcal{F}$ Pediatr 1984; 105: 793-8.

5 Rhondeau SM, Christensen RD, Ross MP, Rothstein G, Simmons MA. Responsiveness to recombinant human erythropoietin of marrow erythroid progenitors from infants with the 'anemia of prematurity'. $f$ Pediatr 1988; 112: $935-40$.

6 Shannon KM, Naylor GS, Torkildson JC, et al . Circulating erythroid progenitors in the anemia of prematurity. $N$ Engl f Med 1987; 317: 728-33.

7 Halpérin DS, Wacker P, Lacourt G, et al. Effects of recombinant human erythropoietin in infants with the anemia of prematurity: a pilot study. $\mathcal{F}$ Pediatr 1990; 116 779-86.

8 Obladen M, Maier R, Segerer H, et al . Efficacy and safety of recombinant human erythropoietin to prevent the anaemias of prematurity. In: Gurland HJ, Moran J, Samtleben W, Scigalla P, Wieczorek L, eds. Erythropoietin in renal and non-renal anemias. Basel: Karger. Contrib Nephrol 1991; 88: 314-26.

9 Shannon KM, Mentzer WC, Abels RI, et al. Recombinant human erythropoietin in the anemia of prematurity: 118: $949-55$. 
10 Ohls RK, Christensen RD. Recombinant erythropoietin compared with erythrocyte transfusion in the treatment of anemia of prematurity. $\mathcal{F}$ Pediatr $1991 ; 119: 781-8$.

11 Beck D, Masserey E, Meyer M, Calame A. Weekly intravenous administration of recombinant human erythropoietin in infants with the anaemia of prematurity. Eur f Pediatr 1991; 150: 767-72.

12 Shannon MK, Mentzer WC, Abels R, et al . Enhancement of erythropoiesis by recombinant human erythropoietin in low birth weight infants: a pilot study. $\mathcal{F}$ Pediatr 1992; 120: 586-92.

13 Carnielli V, Montini G, Da Riol R, Dall'Amico R, Cantarutti $F$. Effect of high doses of human recombinant erythropoietin on the need for blood transfusions in preterm infants. $\mathcal{f}$ Pediatr 1992; 121: 98-102.

14 Rönnholm KAR, Siimes MA. Haemoglobin concentration depends on protein intake in small preterm infants fed human milk. Arch Dis Child 1985; 60: 99-104.

15 Halvorsen K, Halvorsen S. The 'early anaemia': its relation to postnatal growth rate, milk feeding, and iron availability. Experimental study in rabbits. Arch Dis Child 1973; 48: 842-9.

16 Jacobson LO, Marks EK, Gaston EO. Studies on erythropoiesis. XII. The effect of transfusion-induced poly-
cythemia in the mother on the fetus. Blood 1959; 14: 64themia

17 Talbot RB, Swenson MJ. Blood volume of pigs from birth through 6 weeks of age. Am $\mathcal{F}$ Physiol 1970; 218: $1141-4$.
18 Eschbach JW, Egrie JC, Downing MR, Browne JK, Adamson JW. Correction of the anemia of end-stage renal disease with recombinant human erythropoietin. N Engl f Med 1987; 316: 73-8

19 Gairdner D, Pearson J. Growth and development record. Preterm-2 years. Hertfordshire: Castlemead Publications, 1988.

20 Crowder MJ, Hand DJ. Analysis of repeated measures. London: Chapman and Hall, 1990.

21 Hågå $P$. Plasma ferritin concentrations in preterm infants in cord blood and during early anaemia of prematurity. Acta Paediatr Scand 1980; 69: 637-41.

22 Matoth Y, Zaizov R, Varsano I. Postnatal changes in some red cell parameters. Acta Paediatr Scand 1971; 60: 317-23.

23 Stockman JA. Hematopoiesis and granulopoiesis. In: Polin RA, Fox WW, eds. Fetal and neonatal physiology. Philadelphia: Saunders, 1991: 1327-63.

24 Cavill I, Macdougall IC. Erythropoiesis and iron supply in patients treated with erythropoietin. Erythropoiesis: new dimensions in the treatment of anaemia 1992; 3: 50-5.

25 Macdougall I, Hutton RD, Cavill I, Coles GA, Williams JD. Poor response to treatment of renal anaemia with erythropoietin corrected by iron given intravenously. BMF 1989; poietin correcte

26 Becroft DMO, Dix MR, Farmer K. Intramuscular iron-dextran and susceptibility of neonates to bacterial infections. Arch Dis Child 1977; 52: 778-81.

27 Lundström U. Thrombocytosis in low birthweight infants. A physiological phenomenon in infancy. Arch Dis Child 1979; 54: 715-7. 